\title{
THE ELECTROCARDIOGRAM IN HEALTHY EAST AFRICAN (BANTU AND NILOTIC) MEN
}

\author{
BY \\ K. SOMERS AND A. M. RANKIN \\ From the Department of Medicine, Makerere University College, P.O. Box 2072, Kampala, Uganda \\ Received November 20, 1961
}

Several studies have been made of the electrocardiogram in subjects of African origin. In the main these have drawn attention to findings in the RS-T segment in præcordial leads that deviated significantly from the accepted normal patterns.

Littmann (1946) reported the occasional finding of $\mathrm{T}$ wave inversion in the præcordial leads in American negroes. Wasserburger (1955) noted frank inversion in the $T$ waves in 11 per cent of 131 adult negro men. In South Africa, Brink (1951) found similar changes, and in a later exhaustive study (Brink, 1956) of 100 Bantu men and women, 50 of each, he found $T$ wave inversion in præcordial leads as far as V4 in 4 per cent of his subjects. The voltage of the QRS complex was in excess of the criteria of normal in 24 of his 50 male subjects.

Grusin (1954) from Johannesburg reported a 34 per cent incidence of S-T segment changes and $T$ wave inversion in præcordial leads in 159 non-cardiac hospital patients: in addition, he observed spontaneous fluctuations in serial tracings, and also found unusually tall $\mathrm{R}$ waves in left ventricular leads in occasional tracings. In Powell's (1959) series from Durban there was a 37 per cent incidence of S-T segment changes and a 39 per cent incidence of $T$ wave changes in two series of non-cardiac patients: he observed the same changes in 22 per cent of male African nursing staff.

In a small East African study, Turner (1959) found three instances of $T$ wave changes in the right præcordial leads in 50 Kikuyu (Bantu) men. The purpose of this present study is to report findings in a larger study of Bantu and Nilotic East African men.

The Bantu and Nilotic peoples are two major groups of East Africa. The distinction is primarily one of language but there are also differences in physical characteristics and social organization (Goldthorpe, 1958).

\section{METHODS}

The study comprised 209 healthy adult men (154 Bantu and 55 Nilotic), the great majority of whom were in the third decade of life (Table I). Most subjects were University students.

TABLE I

Age Distribution of 209 African Men

\begin{tabular}{lccc|c|c}
\hline \multicolumn{3}{c|}{ Age (years) } & & Bantu & Nilotics \\
\hline$<20$ &. &. &. & 8 & 11 \\
$21-30$ &. &. &. & 128 & 42 \\
$31-40$ & $\ldots$ &. &. & 11 & 2 \\
$41-50$ &. &. &. & 4 & - \\
$>50$ &. &. &. & 3 & - \\
\hline Total &. &. &. & 154 & 55 \\
\hline
\end{tabular}


Small groups were made up by the Uganda Olympic team and various grades of hospital employee. All the subjects underwent a full medical examination including blood pressure reading. Subjects who were not physically healthy were excluded.

A 12-lead electrocardiogram was taken in each case using a Cambridge direct writing machine. The subject lay in the semi-recumbent position. Each recording was calibrated so that $10 \mathrm{~mm}$. was equivalent to $1 \mathrm{mV}$. Sometimes repeat tracings were taken several months after the original tracing. The same technician took all the tracings.

\section{Interpretation of Records}

The criteria of Grusin (1954) as modified by Powell (1959) were considered to enable comparison with the South Africa findings. Our classification of S-T segment was essentially the same as that used by Powell.

Pattern 1. The $\mathrm{T}$ waves were inverted or biphasic in the right and mid-præcordial leads. The S-T segment was usually elevated and was either uniformly bowed upwards or was slightly concave in the initial portion. The end pattern of the S-T segment was usually rounded, terminating in either a frankly inverted or biphasic T wave (Fig. 1).

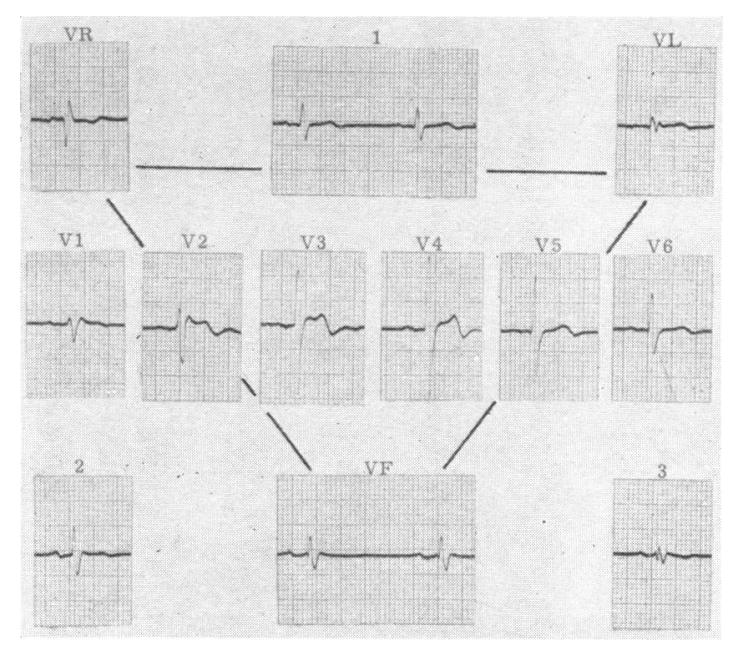

FIG. 1.-12-lead electrocardiogram from a 23-year-old Nilotic showing pattern 1 . The $\mathrm{S}-\mathrm{T}$ segment is elevated in the right and mid-precordial leads, with its end portion rounded. The $T$ waves in these leads are inverted or biphasic.

Pattern 2. The left præcordial leads showed S-T elevation and tall T waves. The S-T take-off was usually high with a slow concave ascent to a pointed $T$ wave which descended sharply to the baseline (Fig. 2).

Pattern 3. This was a combination of pattern 1 and pattern 2 (Fig. 3).

In addition, particular attention was paid to QRS voltage in the præcordial leads as we were impressed with the frequency of left ventricular preponderance in our series. The sum of RV5 and SV1, and of RV6 and SV2 was estimated in each tracing to determine the presence of left ventricular preponderance. This was considered to be present if either of these sums exceeded $35 \mathrm{~mm}$. Each cycle was examined for deviations from the accepted normal in other respects. We compared the findings in the Bantu and Nilotic groups wherever possible. 


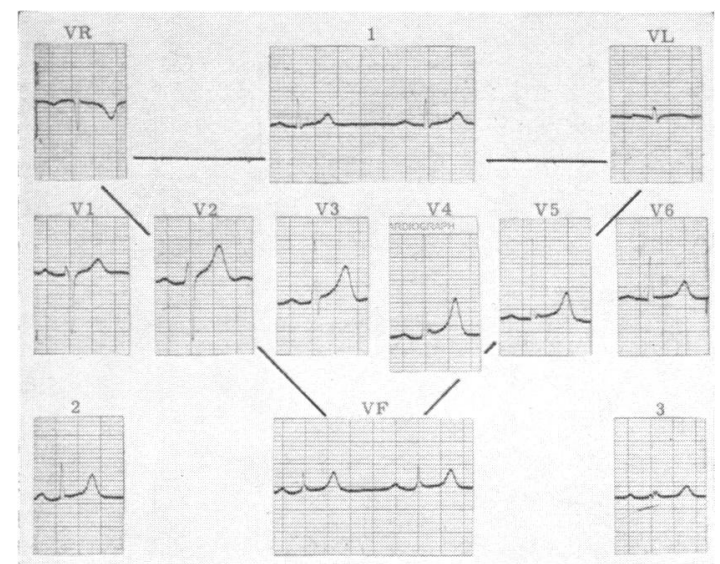

Fig. 2.-Pattern 2 in a 24-year-old Bantu. Note S-T segment elevation in left ventricular leads with concave upward curvature.

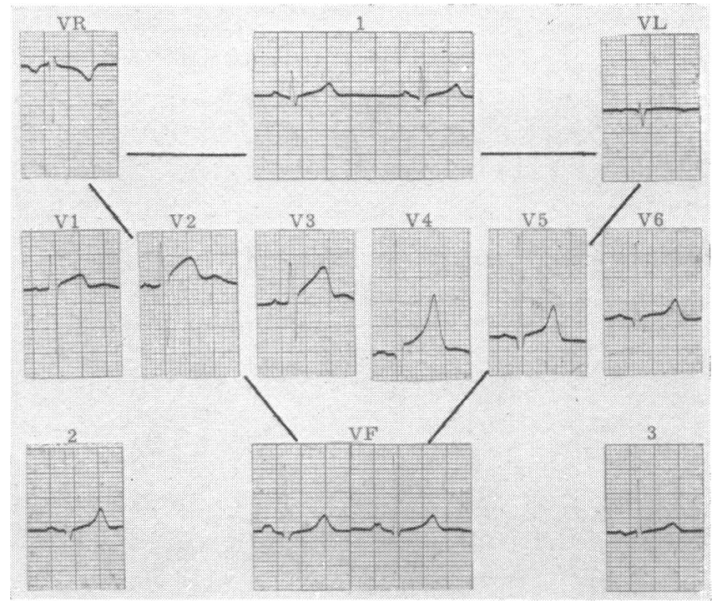

FIG. 3.-Pattern 3 in a 25-year-old Bantu. The S-T segment is bowed upwards in the right ventricular and mid-præcordial leads, and there is an upward curvature of the $\mathbf{S}-\mathrm{T}$ segment in the left ventricular leads.

\section{RESULTS}

Rhythm. No pathological rhythms were found. Sinus arrhythmia occurred frequently, being seen in 71 per cent of the Bantu and 56 per cent of the Nilotics. One Nilotic Olympic boxer exhibited episodes of pre-excitation (Wolff-Parkinson-White syndrome) without tachycardia.

$\boldsymbol{P}$ Wave. With few exceptions this was normal in form. An amplitude of $\mathbf{P}$ in excess of $2 \mathrm{~mm}$. in lead II or III was found in two Bantu and three Nilotics. Bifid P waves not exceeding $0.1 \mathrm{sec}$. in duration were occasionally seen in some leads.

$P-R$ Interval. Excluding one subject each in the Bantu and the Nilotic groups in whom this exceeded $0.24 \mathrm{sec}$. all the subjects showed a normal duration of the $\mathrm{P}-\mathrm{R}$ interval, ranging between $0 \cdot 12$ and $0 \cdot 20 \mathrm{sec}$. (Table II).

TABLE II

P-R Interval (Percentage) in 209 African Men

\begin{tabular}{|c|c|c|c|c|}
\hline \multicolumn{3}{|c|}{ P-R interval (sec.) } & Bantu & Nilotic \\
\hline $\begin{array}{ll}0.12-0.16 & \ldots \\
0.16-0.20 & \ldots \\
0.20-0.24 & \ldots \\
\text { More than } & 0.24\end{array}$ & $\begin{array}{l}\cdots \\
\cdots \\
\cdots \\
\cdots\end{array}$ & $\begin{array}{l}\ddot{.} \\
\ddot{*} \\
\ddot{*}\end{array}$ & $\begin{array}{l}18 \\
79 \\
3 \\
0 \cdot 6\end{array}$ & $\begin{array}{c}37 \\
53 \\
9 \\
0 \cdot 2\end{array}$ \\
\hline
\end{tabular}

QRS Complex. In no instance did we find a pathological $\mathrm{Q}$ wave. There were two instances of right bundle-branch block, one each in the Bantu and the Nilotic groups. In all other tracings the QRS did not exceed $0 \cdot 1 \mathrm{sec}$. in duration.

Distortion, usually splitting of the $\mathrm{R}$ wave, occurred in $17(11 \%)$ of the Bantu and $8(15 \%)$ of the Nilotics. This was most frequently observed in leads V3, VF, III, II, and V5 in decreasing order of frequency.

Left Ventricular Preponderance. A striking feature in both Bantu and Nilotic subjects was the high incidence of left ventricular preponderance (Fig. 4). There were 40 instances $(25 \%)$ in the 


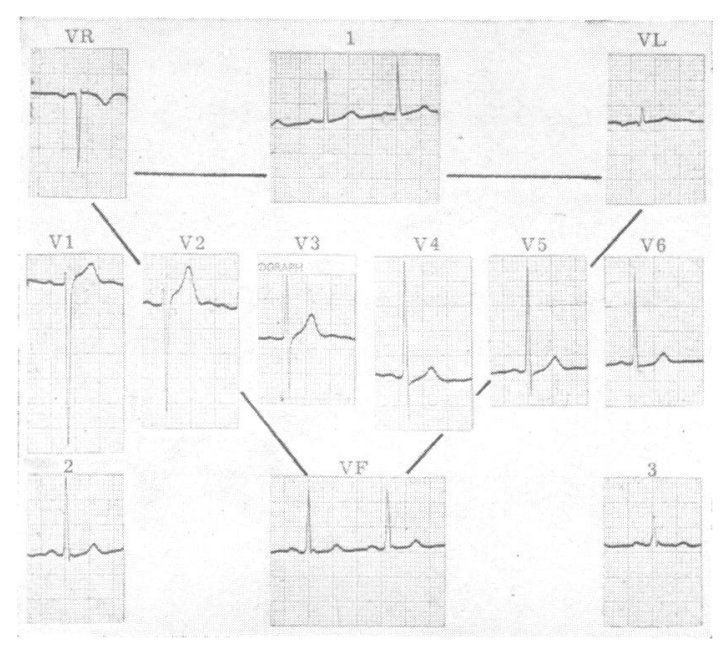

Fig. 4.- Left ventricular preponderance in a 23 -year-old Nilotic. The sum of $R$ in V5 and $S$ in V1 is $57 \mathrm{~mm}$.

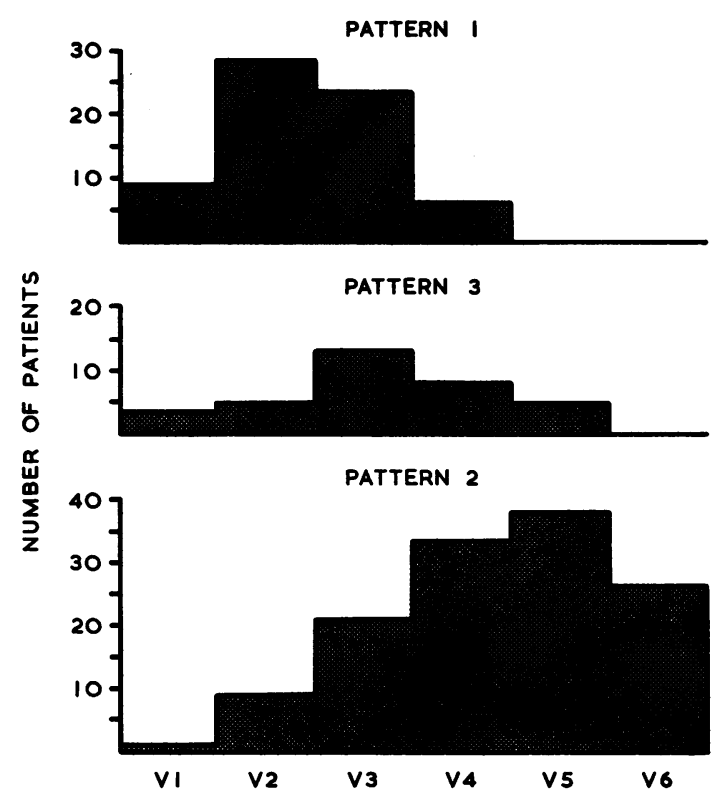

FIG. 5.-Distribution of patterns 1, 2, and 3 in 209 East African subjects.

Bantu and 20 instances $(37 \%)$ in the Nilotics. In several subjects the sum of R in V5 or V6 and S in $\mathrm{V} 1$ or $\mathrm{V} 2$ exceeded $50 \mathrm{~mm}$.

$S-T$ Changes. The S-T segment showed the characteristic changes previously described. The total incidence of deviation from the accepted normal occurred in 68 Bantu $(44 \%)$ and 15 Nilotics $(27 \%)$. Pattern 1, was found in the right and mid-præcordial leads as far as V4, the maximum incidence being in V2 and V3. Pattern 2 in the left præcordial leads was of maximal incidence in V5. Pattern 3, being a combination of pattern 1 and 2 , was most frequently seen in the midpræcordial leads. The distribution of the three patterns of $S-T$ changes in both groups is shown in Fig. 5. 
There was no significant difference in the occurrence of the S-T patterns between Bantu and Nilotics.

$T$ and $U$ Waves. Tall $\mathrm{T}$ waves were frequently observed with pattern 2 in mid-præcordial leads (Fig. 6). In eight (5\%) Bantu subjects and one Nilotic subject $(2 \%)$ the height of $\mathrm{T}$ waves in V2, V3, and/or V4 exceeded $10 \mathrm{~mm}$.

There were no instances of lone $\mathrm{T}$ wave inversion without $\mathrm{S}-\mathrm{T}$ segment changes except those that, occurred as part of pattern 1 .

Unobtrusive $U$ waves were seen in 73 Bantu (47\%) and 24 Nilotics (44\%). They were most frequent in V2, V3, and V4 in both series.

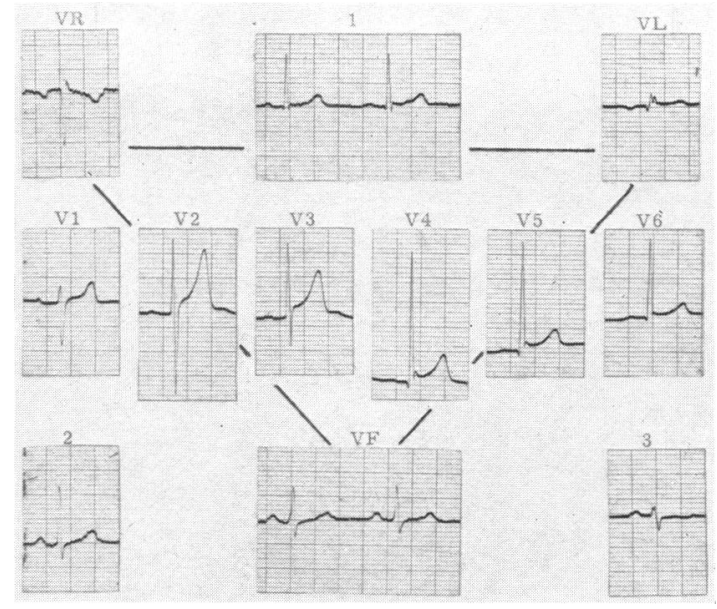

FIG. 6.-12-lead electrocardiogram from a 23-year-old Bantu showing tall $\mathrm{T}$ waves in excess of $10 \mathrm{~mm}$. in V2 and V3. Note also the presence of S-T elevation of pattern 2 type in left ventricular leads.

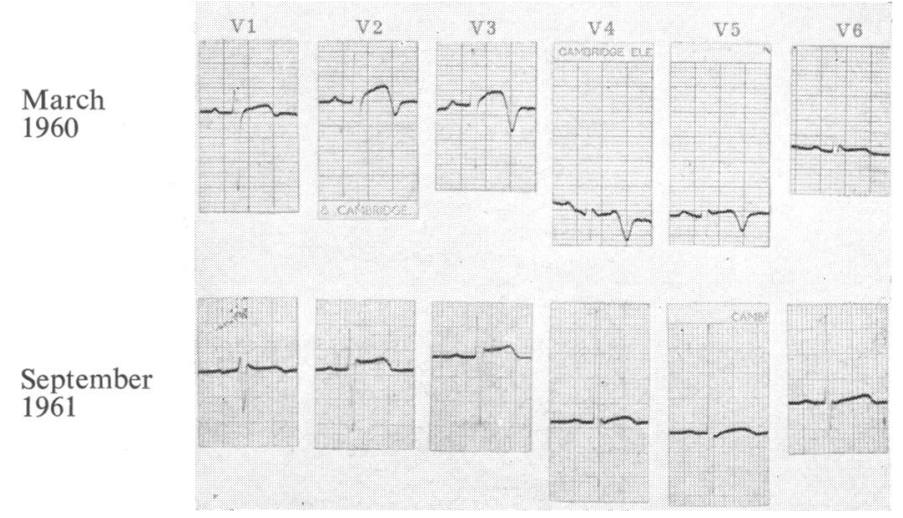

Fig. 7.-Præcordial leads from a 23-year-old Nilotic Olympic boxer. The tracing taken in March 1960 shows striking S-T segment changes of pattern 1 type, and left ventricular preponderance. (Sum of $S$ in V1 and $R$ in V5 is $50 \mathrm{~mm}$.)

Eighteen months later the changes were much less pronounced. 
Serial Studies. In a few subjects serial tracings were obtained. Generally only minor alterations were noted. In one subject however the alteration was striking. He was a 23-year-old Nilotic, a middle weight boxer who had his first electrocardiogram taken after his selection for the Uganda Olympic team in March 1960 . His blood pressure was then $135 / 80 \mathrm{~mm}$. Hg. The tracing showed S-T segment elevation followed by a deep T wave inversion (pattern 1) as far as V5 (Fig. 7). In addition he showed evidence of left ventricular preponderance in that the sum of SV1 and RV5 totalled $50 \mathrm{~mm}$. Eighteen months later there was considerable regression in the pattern of the $\mathrm{T}$ waves in the præcordial leads and in the signs of left ventricular preponderance.

\section{Discussion}

The aim of his investigation was to obtain objective baseline information on normal healthy East Africans. Specifically, we wished to know the frequency of deviation from accepted normal patterns. All our subjects were in good health at the time of examination. No hospital patients were included and in this respect we were at an advantage compared with Grusin (1954) and Powell (1959), who included series of non-cardiac hospital patients in their surveys.

We were aware that the South African surveys had been made on Bantu subjects. We have no reason to believe or disbelieve that Nilotics, who are anthropologically different from the Bantu, would have distinctly different electrocardiograms. In fact our study has shown that the basic patterns are the same in Bantu and Nilotics and occur with a similar incidence in the two groups. Generally speaking the study confirms that S-T segment changes in East African subjects occur with a frequency comparable to those in the two major South African studies reported by Grusin (1954) and Powell (1959). We are of the opinion that the two patterns, pattern 1 and pattern 2, are basically the same. We were impressed by the frequency with which pattern 1 and pattern 2 occurred in the same subject, suggesting that the physiology of production of both patterns is the same.

Because of the resemblance of the S-T segment and $\mathrm{T}$ wave changes in negro subjects to those normally found in young children, Wasserburger (1955) termed it the "juvenile pattern," and cautioned against interpreting it as evidence of myocardial disease. Similar changes have been induced by hyperventilation and abolished by vagal blocking agents (Wasserburger and Lorenz, 1956). The explanation of increased vagal tone seems a plausible one and is supported by Grusin (1954). While this normal S-T segment variant is common in negro subjects, Wasserburger, Alt, and Lloyd (1961) have shown that it is found in only 1 per cent of Caucasian hospital admissions.

We are in agreement with Powell (1959) in considering that the changes cannot be correlated with evidence of liver disease. Our subjects showed no evidence of disease of biliary or other systems.

Elevation of the S-T segment with concave upward curvature is a typical finding in acute pericarditis. These changes are usually diffuse and exactly simulate the normal variant which we have described in pattern 2. Goldman (1953) drew attention to this phenomenon as a frequent occurrence in American negroes. From the study of a single electrocardiogram it may be impossible to differentiate the normal variant from that of acute pericarditis. Clinical evaluation of the patient and serial cardiograms are necessary to differentiate these two conditions.

Præcordial leads provide the most reliable evidence of left ventricular hypertrophy. Using conventional criteria, a very high incidence of left ventricular hypertrophy was observed, 25 per cent in Bantu and 36 per cent in the Nilotics. Similar observations have been noted in Natal Africans (J. V. O. Reid, 1960, personal communication). Why this should be so in subjects with normal blood pressure and clinically healthy hearts requires explanation. Perhaps the answer may be in factors such as an active circulation and thinness of the chest wall. The inference is that left ventricular hypertrophy should be diagnosed with caution in African subjects in the absence of adequate corroborative evidence.

The presence of præcordial $\mathrm{T}$ waves exceeding $10 \mathrm{~mm}$. in height in two or more chest leads is considered to suggest possible myocardial infarction (World Health Organization, 1959). As coronary artery disease is undeniably rare in African communities, we feel that this criterion of 
height of præcordial $\mathrm{T}$ waves as possible evidence of coronary heart disease should be interpreted with due care in such subjects.

\section{SUMMARY}

In a study of 209 normal healthy East African men, S-T segment deviation from accepted normal patterns was observed in 44 per cent of Bantu and 27 per cent of Nilotic subjects. These changes were frequently accompanied by inverted or biphasic $T$ waves in the right and midpræcordial leads. These findings resemble those previously described in the South African Bantu and the American negro, and termed the "juvenile pattern" by American workers.

Left ventricular hypertrophy was also a frequent finding in this series.

We are very grateful to Mr. Robinson Gichuru for the considerable help he has given with records. We thank Dr. John Bennett of the Makerere University College Student Health Service for enabling us to study the student population under his care.

\section{REFERENCES}

Brink, A. J. (1951). An investigation of factors influencing repolarization in the human heart. S. Afr. J. clin. Sci., 2, 288.

- (1956). The normal electrocardiogram in the adult South African Bantu. S. Afr. J. Lab. clin. Med., $2,97$.

Goldman, M. J. (1953). RS-T segment elevation in mid- and left precordial leads as a normal variant. Amer. Heart J., 46, 817.

Goldthorpe, J. E. (1958). Outlines of East African Society. Kampala, Makerere College.

Grusin, H. (1954). Peculiarities of the African's electrocardiogram and the changes observed in serial studies. Circulation, 9, 860.

Littmann, D. (1946). Persistence of the juvenile pattern in the precordial leads of healthy adult negroes. Amer. Heart J., 32, 370.

Powell, S. J. (1959). Unexplained electrocardiograms in the African. Brit. Heart J., 21, 263.

Turner, P. P. (1959). The electrocardiogram in fifty normal young adult Kikuyu males. E. Afr. med. J., $36,555$.

Wasserburger, R. H. (1955). Observations on the 'juvenile pattern' of adult negro males. Amer. J. Med., 18, 428.

-, Alt, W. J., and Lloyd, C. J. (1961). The normal RS-T segment elevation variant. Amer. J. Cardiol., 8, 184.

- and Lorenz, T. H. (1956). The effect of hyperventilation and pro-banthine on isolated RS-T segment and Twave abnormalities. Amer. Heart J., 51, 666.

World Health Organization (1959). Technical Report Series. No. 168. Hypertension and Coronary Heart Disease; Classification and Criteria for Epidemiological Studies. Geneva. 